\title{
Research on the development of rural female human resources under the background of targeted poverty alleviation
}

\author{
Dong Zhaochen ${ }^{1, a}$ \\ ${ }^{1}$ School of Economics and management, Beijing Jiaotong University, Beijing, China \\ a690252276@qq.com
}

Keywords: targeted poverty alleviation, Rural women, Human resources development.

\begin{abstract}
Rural women in China are the important labor force in agricultural production, as well as the nurturer of human resources and the carrier of regeneration. The improvement of the rural female human capital investment is not only related to their own quality and social status, but also plays an important role in rural economic and social development and social progress. Rural women are developed in areas including strengthening basic education, vocational skills training and modern lifestyle, so as to promote the coordinated development of rural economy and society.
\end{abstract}

\section{Introduction}

The development of rural human resources is an important and central part of targeted poverty alleviation. The development of rural human resources and the cultivation of new types of farmers are important guarantees for the realization of the great-leap-forward development of agriculture and the rural economy. At the critical stage of China's entrance into building a well-off society in an allaround way, rural female human resources are not only an important part of rural human resources, but also an important force to promote the development of productive forces, which are related to the realization of the building of a moderately prosperous society in all respects. With the continuous promotion of precision poverty alleviation policies, the government need to adapt poverty alleviation strategies to the reality of rural development, turn poverty alleviation actions into rural selfdevelopment actions, and build rural self-construction capacity and sustainable development capacity. By increasing the development of rural female human resources, the potential of rural women should be stimulated to the greatest extent, so as to fundamentally solve the problem of rural development. Efforts should be made to improve the quality of rural female workers, turn rural female population into rural female human resources, and provide talent guarantee and intellectual support for China to finish building a moderately prosperous society in all respects.

\section{The basic situation of the development of rural female human resources}

\subsection{The educational level of rural woman}

The illiteracy rate varies by gender. According to data from the national bureau of statistics, the proportion of illiterate people aged 15 and above in China was 4.94 percent in 2018, up 0.86 percent from the sixth national census, with females accounting for 7.52 percent and males 2.42 percent. This shows that the gender ratio of illiteracy is quite large, and there remain certain challenges in the female illiteracy elimination in China.

The illiteracy rate also varies according to the region. The illiteracy rate in the central and western regions is higher than that in the eastern regions. The illiteracy rate of rural women in the central and western regions is higher than that in the eastern regions, and the illiteracy rate varies with the economic and cultural development level of different regions [1].In addition, the popularity and quality of pre-school education and early childhood education in rural areas, as well as the influence of some backward family values, make the illiteracy rate of rural women significantly higher than that of men in rural areas with scarce educational resources (Table 1). In 2010, the total number of illiterate people in rural areas decreased by 42.35 percent compared with 2000 , and the proportion of illiterate people in the total population in rural areas decreased by 4.29 percent. The illiteracy rate of 
rural men fell by 2.53 percent and that of rural women by 6.23 percent. However, the illiteracy rate of rural women is much higher than that of men. In 2010, the illiteracy rate of rural women was 2.67 times that of men. It can be seen that although rural women have achieved certain results in literacy, there is still a certain gap between achievement of both sexes.

Table 1. The illiteracy rate of male and female in rural China (population aged 15 and above)

\begin{tabular}{cccccc}
\hline year & gender & The number of illiterate & The total number of & Illiteracy rates & Gender ratio in illiteracy \\
\hline \multirow{2}{*}{2000} & male & 19257277 & 298498800 & $6.45 \%$ & $28.55 \%$ \\
\cline { 2 - 6 } & female & 48188456 & 285324813 & $16.89 \%$ & $71.45 \%$ \\
\cline { 2 - 6 } & sum & 67445733 & 583823613 & $11.55 \%$ & \\
\hline \multirow{2}{*}{2010} & male & 10600149 & 270489242 & $3.92 \%$ & $27.26 \%$ \\
\cline { 2 - 6 } & female & 28284260 & 265303115 & $10.66 \%$ & $72.74 \%$ \\
\cline { 2 - 6 } & sum & 38884409 & 535792357 & $7.26 \%$ & \\
\hline
\end{tabular}

Source: The fifth and sixth census data published on the website of the national bureau of statistics

Rural men have a higher proportion of high school education than women. In 2010 the proportion of rural women with a high-school education rose by 7.17 percent from 2000 (Table 2). In 2000, 6.13 percent of men had a high school education, and 2.90 percent of women had a high school education. In 2010, men with high school education accounted for 9.40 percent of the total number of men, and women with high school education accounted for 5.99 percent of the total number of women. Both men and women have increased in proportion, and the proportion of women has increased more than men, and women's educational levels have gradually enhanced.

Table 2. The gender ratio of high school education among the rural population in China

\begin{tabular}{cccccc}
\hline \multirow{2}{*}{ year } & gender & $\begin{array}{c}\text { Number of } \\
\text { people with high } \\
\text { school education }\end{array}$ & $\begin{array}{c}\text { The total } \\
\text { number of }\end{array}$ & $\begin{array}{c}\text { High school education in the } \\
\text { total proportion of the } \\
\text { population }\end{array}$ & $\begin{array}{c}\text { Gender ratio of high } \\
\text { school education }\end{array}$ \\
\hline \multirow{3}{*}{2000} & sum & 33070572 & 725179200 & $4.56 \%$ & $69.10 \%$ \\
\cline { 2 - 6 } & male & 22851916 & 372860745 & $6.13 \%$ & $30.90 \%$ \\
\hline \multirow{2}{*}{2010} & female & 10218656 & 352318455 & $2.90 \%$ & $61.93 \%$ \\
\cline { 2 - 6 } & sum & 47099999 & 609708623 & $7.73 \%$ & $38.07 \%$ \\
\hline
\end{tabular}

Source: The fifth and sixth census data published on the website of the national bureau of statistics

With the continuous advancement of sustainable development goals in agriculture, China urgently needs to train applied talents in the field of agriculture and use new agricultural technologies for agricultural production. Therefore, skill education for the rural population is particularly important. Through education, the knowledge and skills of rural labor force can be improved, and the knowledge can be transformed into productivity, thus creating value for economic development. With the application of science and technology in agricultural production, rural laborers need to keep pace with the Times and improve their knowledge and skills [2].As more rural men choose to work in cities, if rural women master certain skills in the agricultural field, it is conducive to enhance the stability of agricultural production.

\subsection{Rural women's health}

With the improvement of China's living standard, the life expectancy of urban and rural residents is also increasing. The average life expectancy of Chinese residents in 2018 was 0.39 percent higher than that in 2017.At present, the average life expectancy of women is 79.4 years, 53.78 percent over than 36.7 years when the People's Republic of China was founded [3].As an important indicator of a country's residents' health and medical level, the infant and maternal mortality rates in China have dropped significantly. The infant mortality rate dropped from 34.7 permillage in 1982 to 6.1 permillage in 2018 , and the maternal mortality rate dropped from $80 / 100,000$ in 1991 to $183 / 100,000$ 
in 2018[4]. It can be seen that the health level and quality of life of urban and rural residents have been significantly improved. However, in 2018, the infant mortality rate in rural areas was as high as 7.3 permillage, 1.03 times higher than that in urban areas. The mortality rate of pregnant women in rural areas is 199/100,000, 1.28 times that of urban areas [5].

In addition, due to the neglect of rural women for their own health problems and the delay of disease treatment, some rural women lost the ability to work or even became poor due to illness, which further affected the overall health level of rural women. Compared with urban areas, the health status of rural women still needs attention. With the continuous promotion of targeted (precision)poverty alleviation policy, few people in rural areas are still living on the subsistence line. But the diet structure in rural areas still needs to be improved gradually. Secondly, medical and health conditions and health care concepts directly affect rural women's health. The overall medical and health service system in rural areas lags behind. There is a lack of input in medical and health care and health care services for rural women, and rural women's health problems cannot be diagnosed and treated professionally [6]. Rural women's poor awareness of their own health and health care makes them vulnerable to diseases such as epidemic and gynecological diseases.

\subsection{Employment status of rural women}

The structure of rural labor force changes with the development of rural economy, especially the structure of female labor force. Due to the lack of employment opportunities in rural areas in China, rural women are usually engaged in low-end occupations, such as homemaking or labor-intensive industries with low skills. These jobs tend to be high-intensity, poor working conditions, low-paid, and mostly temporary. Due to the restriction of traditional ideology, social division of labor and physiological characteristics, as well as the imperfect social service system in rural areas, most rural women give up work opportunities because of family care, and the phenomenon of "three more and three less" appears in rural women's employment[7].

\section{The rural female human resources development insufficient reasons}

\subsection{The education degree of the rural woman are below the average level}

Education and training is one of the important ways to improve the quality of human resources and strengthen the development of human resources. The quality of rural women's education is not only related to the sustainable development of human resources, but also to the development of the whole rural economy. Women's education is greatly affected by the economic status of their families. With the continuous progress of targeted poverty alleviation, investment support to rural areas should be increased to provide necessary financial support for rural economic development. The level of rural economy has been improved, and the level of rural women's education and the quality of basic education have also been improved. However, there are many problems in rural teachers, such as low average education level and poor physical and mental quality. The comprehensive quality level of rural teachers is low, and the age structure is middle-aged and elderly. The professional quality and professional ability of rural teachers are poor. At the same time, the educational level of rural teachers is generally low and there are few young and middle-aged teachers, causing difficulties in the development of rural human resources[8].In addition, China's rural areas have lower income levels than towns and cities, and the economy is more backward. The backward economy also makes many rural areas still have the backward idea of " son preference ". Widespread gender attitudes in rural areas have prevented girls from attending school, resulting in a rising drop-out rate for many girls, especially if there are more than one child at home. Girls are more likely to give up the opportunity to receive education to the boys in their families and assume the family responsibilities at home, thus losing the opportunity to receive education. The idea that men are the main bread-earners affects the personal career development of rural women, and the inequality of education and employment harms the rights and interests of women to some extent [9]. 


\subsection{Poor medical and health infrastructure in rural areas}

China's rural health infrastructure is poor, medical and health resources have not been reasonable allocation. Excellent medical personnel and advanced medical instruments and equipment are mostly in large and medium-sized cities, while rural medical facilities and equipment are relatively backward, and there are almost no medical and health resources in poor villages and remote mountainous areas [10].As the basis of rural public health and medical treatment, village clinics lack of overall management and play a weak role in medical protection for rural residents. Village and town clinics still use old medical equipment and weak financial support, but also lack of specialized medical staff, the medical level is generally poor. Due to the lack of doctors familiar with the use of medical equipment in rural health and medical institutions, even with advanced equipment, they will be idle, resulting in the waste of medical resources. The lack of comprehensive ability and quality of doctors, the lack of funds for rural medical treatment, and the low level of financial support, coupled with the farmers' inadequate concept and awareness of medical treatment, lead to a vicious circle of disease and poverty. Many farmers are impoverished or return to poverty due to illness, which seriously hinders rural economic development and farmers' independence from poverty. The team of rural doctors has become a weak link in the rural medical and health service system due to unstable team, inadequate quality, aging and strong mobility. The proportion of rural doctors with technical titles is relatively low, and there are few opportunities for them to receive medical education and training, which leads to the lack of professional ability of rural doctors. Rural doctors with higher professional quality usually set up their own clinics or work in private medical institutions, which further affects the overall professional quality of rural doctors. Due to the poor medical treatment and working conditions at the primary level in China, which is not conducive to the future career development, medical students are not enthusiastic enough to work at the primary level after graduation. The running philosophy of medical schools in colleges and universities lacks a basic-oriented talent training model, which directly leads to the difficulty for medical graduates to go to the basic-level [11].

\subsection{Narrow employment market for rural women}

Rural women play an important role in society and family, but the proportion of rural women receiving higher education is low due to various reasons. In some poor rural areas, even the nine-year compulsory education is difficult to complete, which leads to the low level of knowledge and skills acquired by rural women. Most of the ideas and knowledge they received came from the words and deeds of the previous generation, which led to the transfer of the feudal backward ideas that rural girls acquired from the previous generation of rural women to the next generation. As well as the influence of the traditional social division of labor, the infinite possibilities of rural women's development are limited by the invisible, and the employment space of women is more narrow. The low educational level of rural women leads to the dependence of rural women on their husbands, the lagging social status of rural women and the lack of economic prosperity lead to the low independence of rural women. The range of rural women's activities is mostly restricted in the family, which leads to the narrow access to resources for rural women, who cannot seek welfare for themselves through some resources. The lack of employment in rural areas, the lack of broad employment information dissemination channels, the information system is not smooth, resulting in rural women can not timely access to the labor market information, cannot make the rural female surplus labor force into the city in time, the rural surplus labor force for a reasonable allocation. There are few learning and training institutions for women in rural areas. They are unable to obtain relevant employment information in the labor market in a timely manner, so they are in a weak position in the search for jobs. Most rural areas fail to establish an effective connection with the labor market, so that the surplus rural female labor force cannot find jobs in cities, nor can they meet the urban demand for female migrant workers, nor can the rural female labor force be reasonably allocated [12].The vocational skill training for female migrant workers has not been developed and has formed a scale, and the concept of vocational skill training for rural women is shallow, which also makes it difficult for training institutions to develop. Under targeted poverty alleviation, other rural women need to pay their own way to learn 
knowledge, in addition to training programs targeted at poverty alleviation. Due to the influence of their own needs and concepts, many rural women are less enthusiastic about training and learning, and lack long-term plans for their future career.[9]

\section{Under the targeted poverty alleviation rural women human resources development countermeasures}

According to the anti-poverty strategic positioning of "targeted poverty alleviation", The government should promote the development of rural women's human resources, take rural women as the development objects, activate rural women's human resources, improve their scientific and cultural quality, master certain agricultural technology or vocational skills, enhance their physical quality, and improve the participation rate of rural women in the labor force (Fig. 1).

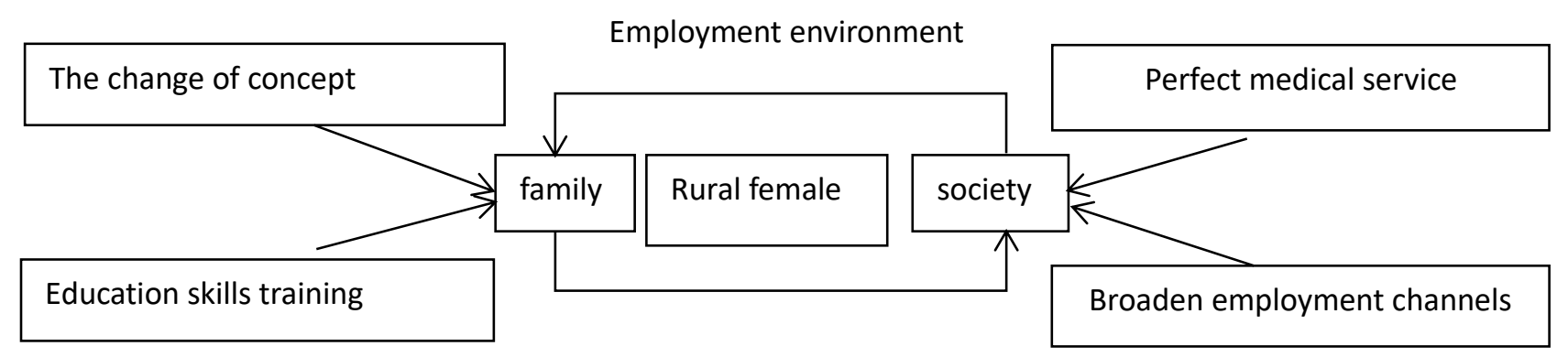

Employment support

Fig. 1. Schematic diagram of rural female human resources development.

\subsection{Ensuring basic education and developing vocational education}

The government should enlighten people if they want people to get rid of the poverty. The government should pay attention to the education level of rural women, make the top-level design of targeted poverty alleviation through education, build a comprehensive system of targeted poverty alleviation through education for rural women, and ensure that targeted poverty alleviation through education truly benefits rural women. The government will comprehensively improve the development of rural education. Education investment, as the most important component of labor capital input, has a direct impact on the development of education, and thus on the quality of labor force and labor productivity. China has made great progress in education, but in remote and poor rural areas, dropouts still exist. In some poor rural areas, targeted poverty alleviation is the overall policy. Strengthening education and narrowing the gap between urban and rural education levels is an important way to develop rural human resources. In order to develop rural women's education, the government should strengthen the guidance and capital investment, improve the allocation of rural education resources, narrow the gap between urban and rural education and gender differentiation, ensure that school-age girls receive compulsory education, and thus improve the overall quality and ability of rural women. Second, rural female labor force has not been fully developed, rural women do not master certain skills, is the biggest obstacle to poverty. Through education, the government can improve the comprehensive quality of rural female workers, promote women to enhance their skills, and master the ability to get rid of poverty and become rich, thus fundamentally intercepting the inter-generational transmission of poverty. Vocational education under targeted poverty alleviation should put people first and earnestly provide education and training of relevant knowledge and skills in accordance with the concept of sustainable development. Starting from the actual needs of rural women, flexible education and training time should be provided to provide agricultural women with education in basic skills, and corresponding agricultural technical education and popularization personnel should be provided for the development of agricultural modernization in rural areas, so as to provide training services for rural women. According to local characteristics, targeted training for rural women. At the same time, rural women can be educated and trained through the Internet, so that rural women can not only acquire skills in time, but also obtain employment information in time. 


\subsection{Attaching importance to women's health and improving medical services}

The rural female labor force under targeted poverty alleviation should not only have certain knowledge skills and living conditions, but also establish scientific health management concepts to continuously improve the health level of rural women. Scientific planning of the distribution of township health clinics, hospitals, to achieve the optimized allocation of medical resources, and actively introduce medical and health personnel, improve the doctor treatment, improve the performance of the system, reasonable distribution of income, increasing the income of doctors and the value of compatibility, and excite the work enthusiasms of doctors, improve the work efficiency effect, fundamentally ensure that farmers can really enjoy the high quality of medical services. While continuing to provide free, targeted training of medical students for medical and health institutions in counties and villages in poor areas, the state should formulate recruitment and introduction measures that meet the actual and requirements of the grass-roots level, focus on improving the working conditions of the grass-roots level medical treatment, improving the development and living conditions of talents, and raising their income level [10].In addition, on the premise of ensuring the physical health of rural women, attention should be paid to the mental health of rural women, the prevention and publicity of mental diseases should be strengthened, and the skills and methods of psychological adjustment should be given to them to enhance the psychological quality of rural women.

\subsection{Expanding employment channels and promoting the development of female human resources}

In the context of targeted poverty alleviation, according to the impact of rural female population on human resource development, this paper tries to solve the problem of rural female human resource development. According to the basic characteristics of the rural areas, rural women human resource development, can from the countryside looking for power itself, to the agricultural industry as the breakthrough point, to encourage the development of rural industry, to provide jobs for rural women employment and development, promote the rural women employment out of poverty, production skills and improve rural women, for rural women and the whole family provides a stable source of income, enhance the sustainable development of family security effectively. In addition, we will encourage women to start their own businesses, provide employment guidance and training, as well as financial support to women who want to start their own businesses, and provide more employment assistance and guidance to rural women who seek employment and lift themselves out of poverty. By creating conditions, we will actively promote and lift women out of poverty through employment. This will be an important way to ensure the sustainable development of families in poor areas and solve women's poverty. It will also be an important way to enhance women's self-development ability, enhance their right to survival and development, and realize all-round human development.

\section{Conclusion}

The state should attach great importance to rural education, and adopt various measures such as increasing rural income and reducing the cost of education for families to prompt the rationalization of the gender ratio of rural men and women at different stages of education and let rural women have an equal right to education. However, there are still some shortcomings in this article, such as the problem of cross-section data-lack of complete dynamic data, so more attention should be paid to dynamic data in future studies.

\section{References}

[1] S. K. Goyal, An integrated inventory model for a single supplier-single customer problem, International Journal of Production Research, vol.15, pp. 107-111, 1977.

[2] Yu Ye, Study on sustainable development strategy of compulsory education in western China, Lanzhou university,2008. 
[3] Peng Shangping, Zhang Tao, Cao Ning. Development of rural vocational education under the background of rural surplus labor transfer, Education and occupation, vol.14, pp. 5-8, 2012.

[4] The state council information office of the People's Republic of China. Equal development and sharing: development and progress of women's cause in 70 years of new China, People's Daily,2019-09-20(010).

[5] National bureau of statistics, Statistical monitoring report of the program for the development of children in China (2011-2020) in 2018, China information news,2019-12-06(001).

[6] Tan Lin, Song Yueping, Migration of women in the context of trade liberalization and its impact on reproductive health, Population research, vol.04, pp. 57-62, 2004.

[7] Wang Junwen, Discussion on the development of rural female human resources in poor areas, Hunan social sciences, vol.06, pp.101-104, 2013.

[8] Zheng Xinrong, Wu Xiaowei. Thinking on the construction and supportive policies of rural teachers in China, Journal of Hebei normal university (education science edition), vol.01, pp.5$10,2014$.

[9] Becker, G.S., A Treatise on the Family, Cambridge, Harvard University Press, 1981.

[10]Feng Kun, Pu Xinxin,Tang Guizhong, Cheng Xuelian, He Zhongchen, Discussion on targeted poverty alleviation path of rural grassroots medical care in China, China health service management, vol.01, pp.47-49, 2008.

[11]Zhao Zhongming, A study on the employment problems and countermeasures of current medical graduates, Southwest jiaotong university,2011.

[12] Mei Shuyuan, Research on improving the ability of rural labor force to go out for employment, Hunan agricultural university,2006. 